\title{
MOVILIZACIÓN, REPRESIÓN Y EXILIO DE JÓVENES ACTIVISTAS NICARAGÜENSES
}

\author{
MOBILIZATION, REPRESSION AND EXILE \\ OF YOUNG NICARAGUAN ACTIVISTS
}

Carlos de Jesús Gómez-Abarca

Recibido: 06/04/2018 - Aceptado: 20/08/2019

\begin{abstract}
Resumen
En este artículo se analiza la crisis sociopolítica que inició en Nicaragua en abril del 2018 a través de los significados y las prácticas políticas de jóvenes activistas enmarcados en tres procesos interrelacionados: el papel de las personas jóvenes en la movilización, la represión y el exilio de jóvenes activistas. El trabajo se basa en una serie de entrevistas realizadas en Nicaragua y en Costa Rica, entre 2018 y 2019, y fuentes secundarias que incluyen trabajos de investigación periodística e informes de organismos de derechos humanos. A manera de conclusión, se reconoce la importancia de las movilizaciones sociales como expresión de un cambio social y como impronta para las nuevas generaciones de activistas.
\end{abstract}

Palabras clave: movimiento social, juventud, migración, Centroamérica, crisis política.

\begin{abstract}
This article analyzes the socio-political crisis that began in Nicaragua in April 2018 through the meanings and political practices of young activists framed in three interrelated processes: the role of young people in mobilization, repression and exile of young activists. The work is based on a series of interviews made in Nicaragua and Costa Rica between 2018 and 2019, and secondary sources that include journalistic research papers and reports from human rights organizations. In conclusion, the importance of social mobilizations is recognized as an expression of social change and as a mark for the new generations of activists.
\end{abstract}

Keywords: social movement, youth, migration, Central America, political crises. 


\section{Introducción}

El exilio consiste, básicamente, en la separación de una persona del lugar en donde habita. Se trata de un tipo de desplazamiento forzado originado por diversos conflictos, la violencia social y política, las persecuciones y las violaciones de los derechos humanos. Durante los siglos XIX y XX, el exilio ha sido una práctica recurrente en diferentes países de América Latina debido a la represión ejercida por las dictaduras a sus opositores y las guerras; ha representado, así, la posibilidad de salvaguardar la integridad física y, en algunos casos, de proteger al agrupamiento político al que se pertenece.

En Centroamérica, las dictaduras militares de finales del siglo XX obligaron a sus ciudadanos a huir a otros países. Con la llegada de las transiciones democráticas y el arribo de gobiernos civiles a la región se registró una relativa disminución de la violencia y con ello una disminución del exilio por motivos de violencia política. Las expectativas de paz y estabilidad eran amplias. Sin embargo, entrado el siglo XXI, presenciamos un repunte de estos desplazamientos forzados en la región, en un contexto caracterizado por la profundización de políticas neoliberales y procesos de securitización.

Según cifras de la Agencia de la Organización de las Naciones Unidas (ONU) para refugiados, 63.5 millones de personas han sido desplazadas de sus hogares debido al conflicto y la persecución a finales del 2015. En este trabajo se realiza una aproximación de tipo comprensiva al exilio que se encuentran experimentando jóvenes activistas nicaragüenses, quienes han salido de su país debido a la violencia generada por los procesos represivos desplegados por el gobierno de Daniel Ortega, en el marco de una jornada de protestas abierta desde el mes de abril del 2018.

Estas protestas fueron detonadas tras una serie de reformas aprobadas, el 16 de abril de 2018, al Instituto Nicaragüense de Seguridad Social (INSS). Según las autoridades, el objetivo de estas era fortalecer el sistema de pensiones mediante la distribución de responsabilidades entre las empresas y los trabajadores, evitar la privatización del servicio prestado a los beneficiarios, mejorar la atención médica para todos y garantizar la seguridad social para la población. Sus detractores, por su parte, cuestionaron la reducción de la pensión de los jubilados y el incremento de cuotas a los trabajadores que implicaban estas reformas.

Las controvertidas reformas fueron canceladas días más tarde por el gobierno de Ortega. Sin embargo, las movilizaciones se incrementaron y la respuesta gubernamental fue el despliegue de una serie de acciones represivas que derivó en una profunda crisis en materia de derechos humanos. Como consecuencia de las estrategias represivas después de un año se contabilizan más de 300 personas fallecidas, 2000 heridos y más de 70000 personas en el exilio, además de cientos de detenciones arbitrarias y torturas, según la actualización sobre Nicaragua de Naciones Unidas para los Derechos Humanos (NUDH), fechada el 10 de julio de 2019. Las consecuencias son 
múltiples y profundas. En este trabajo se analizan tres procesos interrelacionados: la movilización social, la represión y el exilio, se pone el foco de atención en el papel de las personas jóvenes activistas nicaragüenses.

El principal sustento empírico está constituido por seis entrevistas realizadas con activistas de Nicaragua, tres de estas realizadas en Managua, Nicaragua, y las otras tres en San José, Costa Rica. Adicionalmente, el trabajo se ha nutrido de una serie de observaciones previas realizadas durante el proceso electoral de Nicaragua en el 2016, posteriores diálogos informales con activistas y académicos que han participado o seguido las movilizaciones sociales y la revisión exhaustiva de testimonios, informes y análisis publicados entre 2018 y 2019.

Para el análisis de las entrevistas se ha utilizado el programa atlas.ti versión 7.5.4. En un primer momento, la movilización, la represión y el exilio, resultaron categorías útiles para ordenar la información en términos temáticos y cronológicos, y, al mismo tiempo, ofrecieron la posibilidad, a través de mapas conceptuales, de establecer interconexiones. Finalmente, se identificó la necesidad de incluir una perspectiva generacional como marco amplio para la comprensión de los activismos contemporáneos en Nicaragua.

El texto está dividido en cinco partes. En la primera se revisa una serie de premisas teórico metodológicas que orientaron la aproximación a los significados y las prácticas de jóvenes activistas; en un segundo momento, se aborda el papel de las personas jóvenes en las movilizaciones; en tercer lugar, se exponen los procesos represivos desplegados en contra de los manifestantes; en cuarto, se aborda el proceso de exilio de las personas jóvenes activistas nicaragüenses; después, se presenta la controversial Ley de Amnistía que enmarcó las liberación de activistas en 2019; y, finalmente, a modo de conclusiones, se exponen algunos de los principales desafíos abiertos para los activistas en la compleja crisis sociopolítica nicaragüense.

\section{Referentes teórico metodológicos}

Esta investigación forma parte de un quehacer investigativo más amplio que tiene el objetivo de contribuir a la comprensión, en general, de la relación existente entre los movimientos sociales y las instituciones del Estado en el sur de México y Centroamérica ${ }^{2}$, en particular, del papel de las personas jóvenes como sujeto político en los conflictos y procesos sociopolíticos en estas regiones. De ahí que en este trabajo se ofrezca un análisis del papel sociopolítico que tienen las personas jóvenes nicaragüenses, un sector de la población que, por un lado, experimenta con particular intensidad los déficits democráticos en diferentes regiones de América Latina y, por otro lado, expresa un protagonismo en la arena política en las últimas décadas.

En concreto, desde este estudio se pretende aportar claves para comprender la constitución de las personas jóvenes nicaragüenses como sujetos políticos en un 
contexto caracterizado por una creciente represión. En este contexto, las personas jóvenes han tenido un protagonismo que evoca el papel que tuvieron durante la Revolución sandinista en la segunda mitad del siglo XX, pero, al mismo tiempo, expresan rupturas y descontentos con el gobierno encabezado por Daniel Ortega y Rosario Murillo. Su participación revela, así, una tensión existente entre las diferentes formas sobre el pensar y hacer la política, lo político y lo democrático.

La tensión entre continuidades y rupturas expresadas por las generaciones más jóvenes ha sido históricamente motivo de preocupación de cualquier Estado. Desde las Ciencias Sociales, la perspectiva generacional se ha desarrollado en diferentes vías, entre las que destacan, por un lado, la perspectiva sociodemográfica, que ha colocado el foco de análisis en las cohortes de edad y, por otro, la perspectiva sociohistórica que ha situado su interés en la vinculación de los sujetos en la construcción significativa de experiencias "epocales" compartidas. En este trabajo me distancio de la primera, para concentrarme principalmente en la segunda.

Cabe comenzar con una precisión del término generación que orienta transversalmente el análisis de este trabajo y su adjetivación política. Sobre la primera, Comte y Dilthey fueron dos autores que, pese a sus diferentes perspectivas, desde el siglo XIX establecieron bases para posteriores desarrollos analíticos. No obstante, sus trabajos no plantearon abiertamente el tema de las nuevas generaciones: las personas jóvenes, como sí lo hicieron más adelante en los albores del siglo XX José Ortega y Gasset y Karl Mannheim (Caballero y Baigorri), quienes abrieron posibilidades analíticas para futuros trabajos.

Para Ortega y Gasset las transformaciones de orden material son consecuencias de ideas y preferencias, pero, al mismo tiempo, la ideología y la moralidad son resultado de cómo se siente la existencia, de la sensibilidad vital que varía en función de la época (1923). Desde esta óptica, las variaciones en la sensibilidad vital se presentan bajo formas generacionales: “La generación, compromiso dinámico entre masa e individuo, es el concepto más importante de la historia, y por así decirlo, el soporte sobre la que esta ejecuta sus movimientos" (Ortega y Gasset 147).

La sucesión de generaciones sería, en este sentido, expresión vital de la evolución de un pueblo que se mueve en dos dimensiones: recibir lo vivido por la generación antecedente y dejar fluir su propia espontaneidad. Cuando existe suficiente homogeneidad entre ambas, se experimentan épocas acumulativas; mientras que cuando existen grandes diferencias se viven tiempos de ruptura. Las épocas podrían estar dirigidas por los ancianos, o bien, podrían ser tiempos de jóvenes, edades de iniciación y beligerancia constructiva. Esta definición incluye cinco periodos de quince años: la niñez, la juventud, la iniciación, el predominio y la vejez (Ortega y Gasset).

Entre las principales críticas que se le hicieron a esta propuesta, se encuentra la determinación de quince años como medida cuantitativa de generación y la constancia que supone la sucesión de estas etapas (Martínez Codes). No obstante, esta propuesta 
ha sido ampliamente trabajada y expone avances para pensar desde una perspectiva histórica las generaciones. En este trabajo, resulta útil para pensar las continuidades y rupturas experimentadas por las y los jóvenes nicaragüenses.

Otro mérito importante en la propuesta de Ortega y Gasset, a decir de Bauman, fue destacar la superposición entre generaciones, de lo cual se deriva que no todos los contemporáneos se pueden considerar como parte de una misma generación. Al respecto, Karl Mannheim aportó elementos innovadores rechazando cualquier formulación matemática que buscara establecer el cambio generacional de manera lineal y cronológica, y enfatizando el peso de los factores estructurales en la configuración del pensamiento y el conocimiento humano. Mannheim consideró a la generación analíticamente importante para el estudio de las dinámicas de cambio social $\mathrm{y}$, al mismo tiempo, las generaciones eran consideradas como producto del cambio (Caballero y Baigorri; Leccardi y Feixa).

La construcción del concepto de generación, según Mannheim, podría entenderse en tres dimensiones: 1) la posición generacional, fundamentada en la existencia del ritmo biológico, vinculado a la edad, en la cual los individuos están sujetos a las mismas fuerzas determinantes sociohistóricas; 2) la conexión generacional, referente a la vinculación concreta, como una participación en el destino común de esta unidad sociohistórica, en el espíritu de la época; y 3) la unidad generacional, todavía más concreta, expresada en grupos que implican vivencias, sentimientos y actitudes diversas y distintas dentro de un mismo momento histórico real (Mannheim).

Entre las principales críticas a la perspectiva mannheimiana se argumenta que existe una sustitución del conflicto de clases por el conflicto generacional. Las generaciones serían interpretadas desde una perspectiva del conflicto intergeneracional para explicar el surgimiento de fuertes transformaciones impulsadas por las personas jóvenes quienes serían poseedores de otras formas de entender el mundo, lo cual se traduce en el deseo de romper los esquemas construidos por generaciones anteriores (Caballero y Baigorri). No obstante, esta propuesta ha representado un aporte fundamental para entender las variaciones en el tiempo de las formas de producción de los sujetos, sus condiciones materiales y sociales (Pérez-Islas).

En cuanto a la adjetivación política de las nuevas generaciones o las formas en que se expresa esta politicidad no debe ser entendida como algo inherente a la condición juvenil, sino como resultado de un proceso de politización individual y colectivo. Como corolario de esta premisa, las personas jóvenes no son por naturaleza reproductores de la realidad social, ni promotores de cambio. Su constitución como sujetos políticos se enmarca en procesos de (inter)subjetivación y socialización, en los cuales los padres, la escuela, los pares, los colectivos y los medios de comunicación son algunos de los referentes fundamentales.

Por lo anterior, en este trabajo se ha optado por una perspectiva comprensiva que, sin dejar de triangular y contrastar múltiples fuentes de información secundarias 
y elementos contextuales e institucionales, esté basada principalmente en la elaboración simbólica de los propios activistas. Esto implica reconocer que los activistas son reproductores y productores de un universo de significados políticos que motivan y se despliegan a través de sus acciones y que el investigador es un ser humano que escucha, observa e interpreta a partir de su experiencia, sus prenociones y los supuestos teóricos con los que inicia la indagación.

Como parte de este ejercicio hermenéutico se emplean también nociones desarrolladas en los estudios de los movimientos sociales para el estudio de los activismos juveniles. En este heterogéneo subcampo de estudio se abren paso el análisis de la construcción social del agravio que permite aproximarse a las estructuras cognitivas que orientan los repertorios de acciones colectivas, revelando el sentido que adquiere ser ciudadano y activista en la arena pública actualmente.

Todo lo anterior, finalmente, termina abonando a la comprensión de lo que implica ser activista en entornos represivos, tema que ha dado lugar a múltiples esfuerzos analíticos que buscan determinar el carácter restrictivo o facilitador del contexto para las acciones colectivas. Si bien en primera instancia, se aduce que una mayor represión incrementaría generalmente el costo de la participación en las protestas precipitando el desenlace de los movimientos, esto no siempre ocurre; en ocasiones la violencia contra los manifestantes suma nuevos simpatizantes, dando legitimidad al movimiento y deslegitimando a los Estados (Flesher y Wood). ¿Cuáles han sido las repercusiones tras la represión en Nicaragua? Es una pregunta que se suma al análisis que aquí se propone.

\section{Personas jóvenes y movilización social}

Las movilizaciones que comenzaron en 2018 en Nicaragua y la ulterior crisis social y política revelan un punto de inflexión en la historia contemporánea de este país que puede ser analizado a partir del papel que tienen las personas jóvenes en estos procesos. El papel de los jóvenes ha sido fundamental en la historia reciente de América Latina. En Nicaragua, particularmente, han estado en primera fila antes y después de la Revolución sandinista (Martí i Puig, 2017; Salgado), y continúan teniendo un peso significativo tanto en el plano electoral como en los movimientos sociales que han sido críticos al gobierno sandinista.

Las personas jóvenes que han participado de estos movimientos sociales son en su mayoría personas que se encuentran entre los 20 y 30 años de edad, es decir, que nacieron entre 1989 y 1999. Enmarcar el rango de edades en el cual se sitúan estos activismos resulta de importancia para aproximarse a la experiencia social y política de estos jóvenes. Si consideramos, los referentes que constituyen el espíritu de la época de los años noventa del siglo XX, se puede decir que se trata de una generación que es hija de la transición democrática marcada por la llegada al poder de Violeta Barrios de Chamorro en 1990. 
La llegada de Barrios de Chamorro, marcada por la participación de todos los partidos políticos, una lógica competitiva entre estos y la presencia de observadores internacionales, representa un punto fundacional en la historia democrática de Nicaragua (McConnell, citado en Martí i Puig, 2016). Con el relevo del poder y con un proyecto que reposaba sobre tres grandes ejes -1) el Estado de derecho, 2) el sistema electoral competitivo y confiable y 3) el monopolio legal de la fuerza, con la profesionalización e institucionalización de las fuerzas armadas y de la policía- se avizoraban aires de cambio para poner fin a la larga guerra interna, impulsar y mejorar la economía y, en consecuencia, para establecer condiciones verdaderamente democráticas (Cuadra; Jarquín).

Las amplias expectativas, sin embargo, serían cortadas en las próximas décadas por el retorno del sandinismo al gobierno, en una nueva fase caracterizada por un proceso de desdemocratización y centralización del poder (Bataillon; Martí i Puig, 2019). El siguiente extracto de una reflexión de una joven activista es significativo en tanto que revela una posición generacional y los referentes políticos y económicos que han marcado la historia contemporánea de Nicaragua, así como una participación activa en el destino común de esta unidad sociohistórica, en el espíritu de la época de fines del siglo XX y lo que va del siglo XXI:

¿Cómo se sentiría vivir en un lugar que no te violente todo el tiempo? Los conflictos armados, la desigualdad, la corrupción y el caudillismo han marcado la vida de generaciones enteras de centroamericanas. Nosotras somos las nietas de quienes protagonizaron el derrocamiento del dictador Anastasio Somoza, las hijas de quienes huyeron de la guerra o el hambre, somos también hijas de la crisis neoliberal. Fue nuestra generación la que vio en el retorno del FSLN un propio triunfo, nuestra propia victoria, la recompensa de tantos años de esperanza arrebatada. Catorce años después no nos reconocemos en ese pasado, los caudillos del Frente Sandinista nos han traicionado una vez más. Ha sido nuestra generación la que se levantó contra los Ortega atrincherándose en las calles de todos los departamentos de Nicaragua, encarnando la repetición de la historia (Amanda, comunicación personal, octubre de 2018).

No obstante, podría alegarse que no todas las personas nacidas en determinado periodo de la historia comparten la misma visión del mundo a pesar de ser testigos de los mismos acontecimientos históricos y que prueba de ello es el antagonismo entre la "juventud sandinista" y opositores fragmentados por una diversidad de idearios políticos de los movimientos sociales, en general. En efecto, este texto como cualquier otro, está condenado a un análisis de la parcialidad de los sectores juveniles nicaragüenses, de tal forma que es necesario recurrir a la identificación de vivencias y sentimientos compartidos que permiten reconocer, analíticamente, posibles unidades generacionales.

Este trabajo recupera la visión de hombres y mujeres jóvenes activistas cuya vinculación, en primera instancia, radica en su posicionamiento político de oposición 
al gobierno sandinista, lo cual los ha impulsado a mantener un protagonismo en el seno de la actividad política en universidades y fuera de estas. Se trata de activistas que desde adolescentes han enarbolado diferentes causas, adscribiéndose al movimiento feminista, el movimiento por la diversidad sexual, el movimiento ecologista y a los movimientos en defensa del territorio.

La experiencia militante en la juventud sandinista es algo recurrente entre los activistas movilizados desde 2018. Bayardo, por ejemplo, fue miembro de la Juventud Sandinista, pero en el año 2009 decidió renunciar a la filiación del Frente debido a que los proyectos por la defensa y la extensión de los derechos que venía realizando fueron bloqueados por el gobierno sandinista, cerrándose, por ejemplo, las 48 Casas Municipales de Adolescentes abiertas entre 2006 y 2009, donde se discutían temas políticos, de educación, salud y recreación.

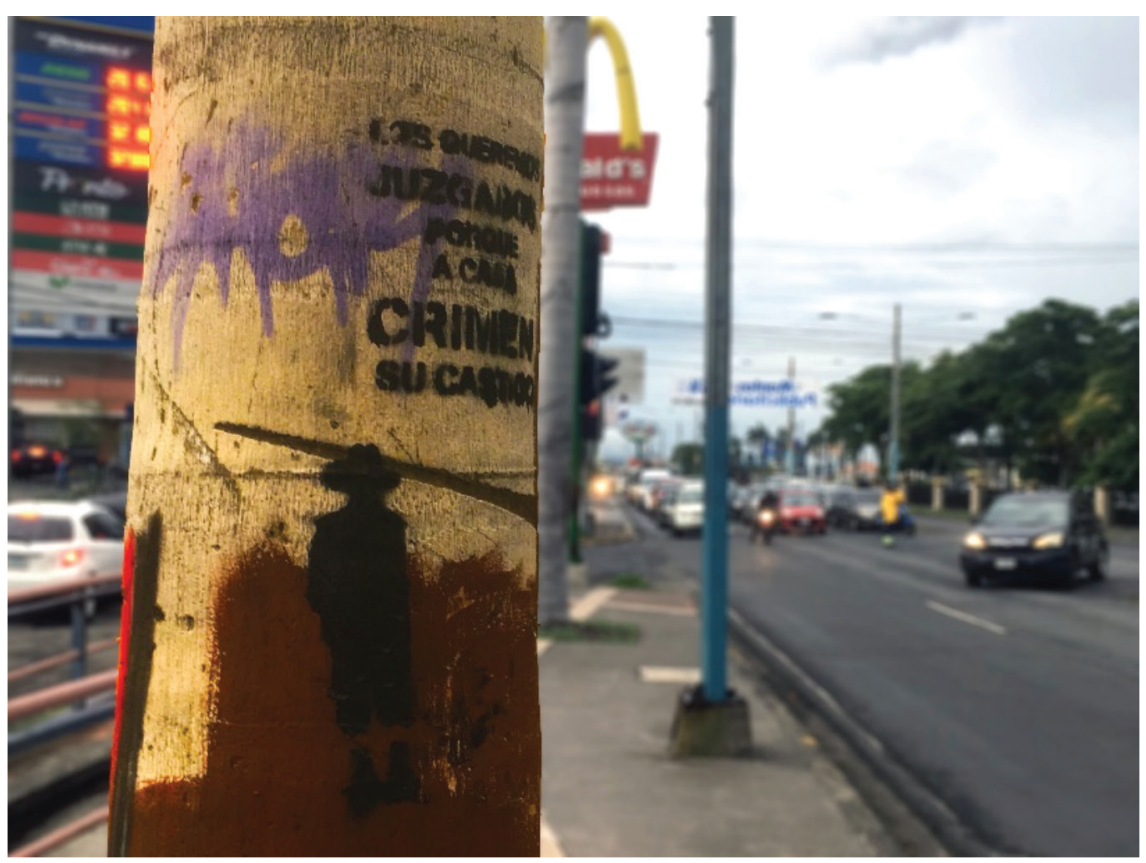

Fuente: Elaboración propia.

El distanciamiento de Bayardo con el Frente Sandinista de Liberación Nacional (FSLN) y su posicionamiento crítico en torno al gobierno de Daniel Ortega no es un caso aislado. El alejamiento que experimenta un amplio sector de jóvenes con respecto 
al gobierno sandinista se enmarca en una serie de cuestionamientos de diferente índole que han implicado la ruptura de las personas jóvenes con el gobierno sandinista, lo cual también ha provocado diferentes rupturas al interior de las familias y la sociedad nicaragüense. La Figura 1 expresa tal ruptura con el sandinismo-gobierno a través de la exigencia de justicia en el contenido textual de la gráfica política ("Los queremos juzgados porque a cada crimen su castigo"), y, al mismo tiempo, la persistencia de los valores sandinistas, en la parte icónica de la misma intervención gráfica.

Esta ruptura con el sandinismo-gobierno es una clave para reflexionar sobre los motivos de las protestas más importantes del siglo XXI en Nicaragua. "Nicaragua era una olla de presión que en algún momento tenía que explotar" es un recurso retórico recurrente de los activistas entrevistados, una expresión muy orgánica del movimiento que evoca la construcción social del agravio, entendido como la elaboración de los diagnósticos sobre la realidad social de los actores y la identificación de los responsables de la situación en la cual se encuentra la población agraviada. Esta elaboración está atravesada por un fuerte componente moral, caracterizada por un conjunto de principios de justicia que orientan las acciones de manera explícita, o que se presentan en forma de intuiciones (Jasper; Meneses).

En este proceso, Jasper destaca la importancia de los choques morales, entendidos como eventos o información tan perturbadora que provocan que las personas que no se dedican de tiempo completo a la política sean reclutadas con mayor facilidad, dando un fuerte impulso al movimiento. Muchas veces la acción política es resultado de la actitud de desesperanza. Posteriormente, los activistas intentan generar transformaciones morales por medio de su propia propaganda, por ejemplo, a través de imágenes alarmantes o historias de crueldad y opresión.

En esta línea argumentativa es importante comprender el sentimiento de agravio, que es recurrentemente un resorte de la acción colectiva (Meneses). Si bien los agravios morales no explican, ni determinan del todo a la acción colectiva, son argumentos esgrimidos por los actores movilizados en defensa de sus propias acciones de defensa. A partir de las entrevistas sostenidas con los activistas que han participado en las jornadas de protesta en Nicaragua en 2018, se puede reconstruir los agravios, los perpetradores de estos y los sentidos de agravio que han sido la chispa que detonó las movilizaciones.

Los diagnósticos que realizan los activistas y la lista de agravios que enumeran son unánimes entre las personas entrevistadas. Entre las principales coyunturas que han venido tensionando las relaciones entre la sociedad y el gobierno, se evocan al menos tres: los cuestionamientos a la aprobación del Gran Canal en la segunda década del siglo XXI, las polémicas elecciones desarrolladas en 2016, la ineficiente respuesta gubernamental ante el incendio de la Reserva Indio Maíz y las recientes reformas a la Ley de Seguridad Social, en abril de 2018; adicionalmente se encuentran otros agravios identificados de manera específica por diferentes movimientos sociales. A continuación, bosquejo estas tensiones. 
A comienzos de la segunda década del siglo XXI, se reactivó la propuesta del Gran Canal, un proyecto de canal marítimo que pretende conectar el mar Caribe, en el océano Atlántico, con el océano Pacífico a través de territorio nicaragüense. Con este proyecto, el gobierno prometió incrementar el comercio entre América Latina y Europa, y entre China, Brasil y Europa. Esta obra fue respaldada por la Asamblea Nacional de Nicaragua decretando la Ley 840 que otorga la concesión de la construcción y la administración a la empresa china HKND Group.

El proyecto contó con fuertes oposiciones debido a la unilateralidad con la que fue aprobado por Daniel Ortega, el daño ecológico que implicaba su construcción en el territorio y la falta de ventajas que representaba para el país. En 2014, diversos sectores de trabajadores, organizaciones civiles que forman parte del Movimiento por Nicaragua, grupos ambientalistas y campesinos se movilizaron en diferentes partes del país para demandar la derogación de la Ley 840. El gobierno, por su parte, apostó por la intimidación y obstaculización de las manifestaciones. Una de sus estrategias fue la organización de una marcha con la consigna “Trabajo y Paz, Unida Nicaragua Triunfa" conformado por simpatizantes del Frente Sandinista.

Otra coyuntura de fuertes tensiones se experimentó en el 2016, en el pasado proceso comicial donde se eligió al presidente y vicepresidente de Nicaragua, 90 diputados nacionales y 20 representantes del Parlamento centroamericano. ${ }^{3}$ El escenario preelectoral estuvo caracterizado por múltiples y controvertidos acontecimientos que fueron desarrollándose en desmedro de la legitimidad de los comicios, tales como: 1) la ausencia de una oposición real al presidente Daniel Ortega que buscaría su cuarto periodo de gobierno y el tercero consecutivo; 2) la candidatura de su esposa Rosario Murillo como vicepresidenta de la misma fórmula; 3) el excesivo uso de propaganda política, muchas veces operada por fuera de la normativa; y 4) las dificultades que se plantearon a observadores nacionales e internacionales. Todo esto definió un contexto político altamente inestable.

La observación preelectoral de algunos organismos denunciaba inconsistencias que desacreditaban las elecciones a celebrarse. Un día antes de los comicios, el Consorcio Panorama Electoral (CPE) emitió el IV Informe Preelectoral Sistemático (2016). En este, se documentó la persistencia de defectos que marcaron el comienzo del proceso electoral, entre los que se incluyen y detallan: el abuso de los recursos del Estado por el FSLN de forma continua, ampliada y sistemática; la baja calidad de la actividad de campaña que reflejaba una elección carente de una competencia real; y el bajo nivel de las actividades de educación electoral al votante, conducida por el Consejo Supremo Electoral (CSE).

La lectura del Frente era triunfalista, basada en las tendencias de votación les beneficiaban con el 64.3 por ciento de las votaciones y una participación esperada del 75 por ciento. El título de la portada del N. ${ }^{\circ} 258$ de la revista Visión Sandinista, correspondiente al mes de octubre de 2016, "A votar y ganar con Daniel", es altamente 
significativo en este sentido. Las elecciones nacionales se caracterizaron, según la versión oficial, por ser ordenadas, tranquilas, pacíficas, plurales, transparentes y alejadas de la confrontación y la estridencia mediática y comercial en la que el capitalismo ha convertido los procesos electorales en el mundo (Franco).

No obstante, en el escenario preelectoral de octubre de 2016 se percibía una confusa dualidad (Ramírez). Dos historias se escribían simultáneamente disputándose la narración de lo que ocurriría durante y después de los comicios. Por un lado, "la crónica de una farsa electoral anunciada", escrita por los detractores del orteguismo; por el otro, la historia escrita desde la óptica del FSLN, desde la que todo lo que no apoyaba el triunfo arrasador del Frente es malo, inexistente o imperialista. Durante estos comicios se exacerbó la polarización sociopolítica, lo cual provocó el incremento en los niveles de desconfianza ciudadana.

Después de la jornada electoral, en el tercer y último informe sobre los resultados oficiales en Nicaragua ofrecido por el CSE el 7 de julio, se señalaba, con el $99 \%$ del total de las Juntas Receptoras de Votos, que el FSLN ganó la Elección Presidencial con el $72.75 \%$ de los votos, la Elección de Diputados Nacionales con el $66.8 \%$, la Elección de Diputados Departamentales con el 65.7 \% y la Elección de Diputados al Parlamento Centroamericano con el $66.2 \%$. Estas cifras fueron cuestionadas posteriormente por diferentes actores políticos.

Un día después, el CPE emitió un informe preliminar de los comicios donde confirmó la ausencia de una competencia genuina y debilitada, así como también la falta de credibilidad y transparencia. Con respecto a la competencia destacaron las irregularidades en el proceso de cedulación, la eliminación de la dirigencia del principal partido opositor, reformas legales que permitieron la asignación de curules al partido y no a la persona electa por los ciudadanos, la dificultad de campañas opositoras para obtener financiamiento y el abuso de bienes del Estado y Recursos Humanos. Respecto a la credibilidad y transparencia, destacaron la cuestionable credibilidad del árbitro electoral y la previa remoción de garantías de transparencia.

Un tercer punto de tensión se generó a partir del 3 de abril de 2018, durante el incendio de la reserva biológica Indio Maíz, ubicada al suroriente del país. Este desastre natural ha sido controvertido, particularmente por las magnitudes del desastre y sobre la eficiencia de la intervención que realizó el gobierno. Este acontecimiento provocó la participación de organizaciones ecologistas y estudiantes universitarios, quienes argumentaron que no se estaba dando solución oportuna al problema. Diferentes activistas colocaron, a través de sus consignas, la sospecha de que tal incendio pudo haber sido provocado, dado que se encuentra ubicado justamente donde inicia la ruta del Gran Canal.

Otra fuente de tensiones es la violencia ejercida contra diferentes movimientos sociales, tal como refieren activistas del movimiento feminista. Aunado a la creciente violencia expresada en los feminicidios en los últimos años y la represión 
experimentada por mujeres que hacen parte de las organizaciones sociales, se suma la aprobación de leyes que representan un retroceso en materia de derechos de las mujeres, como la prohibición del aborto terapéutico, derogado a finales de 2007. Para Gomes, en los últimos años el sandinismo, en función de su alianza con la Iglesia católica, ha restringido las oportunidades políticas para las movilizaciones y protestas, lo cual ha dificultado la organización de las jóvenes y la movilización de consignas feministas.

En resumen, las movilizaciones de 2018, desde la perspectiva de la oposición, son producto del descontento acumulado entre diferentes sectores sociales, en ese sentido, el proceso electoral de 2016 es un hito para comprender la pérdida de legitimidad del gobierno de Daniel Ortega entre los ciudadanos nicaragüenses. Sin embargo, también deben considerarse un cúmulo de agravios que diferentes movimientos sociales - por la diversidad sexual encabezado por la comunidad LGBTTTIQ+, ambientalista, en defensa de la tierra y el feminista- han denunciado en los últimos años, visibilizando las prácticas xenofóbicas, misóginas, neoextractivistas, neoliberales y represivas del gobierno orteguista.

Este cúmulo de agravios explica, parcialmente, el creciente descontento social y el protagonismo estudiantil-juvenil como parte toral de las movilizaciones de 2018. La organización y determinación que desplegaron las personas jóvenes estudiantes en diferentes regiones del país posibilitó la generación de un movimiento social de carácter espontáneo y desarticulado denominado Movimiento Universitario 19 de abril (MU-19A), tal como queda expresado en los siguientes extractos.

[En el contexto del incendio de Indio Maíz] Las universidades se levantaron, comenzaron a aparecer grupos de "activistas emergentes". Y comenzaron a organizar plantones, protestas, movilizarse en diferentes lugares simbólicos, diciendo jse está quemando Indio Maíz, andá decirle a Daniel Ortega! (Bayardo, comunicación personal, septiembre de 2018).

[Con respecto al movimiento 19 de abril] Fuimos los jóvenes, estudiantes, universitarios quienes lideramos todas estas protestas. ¿Qué ha pasado? Como no había un movimiento articulado desde antes, muchos de los jóvenes se articularon, se autonombraron (Ximena, comunicación personal, septiembre de 2018).

Las expresiones colectivas fueron diversas. Para su exploración, recuperamos la noción de repertorios de acciones colectivas o repertorios de activismo. La noción tradicional de repertorios de protesta se puede entender como un conjunto de rutinas usadas convencionalmente por los demandantes para llamar la atención sobre sus demandas y exigir su cumplimiento, caracterizadas como conductas que se encuentran por fuera de las vías institucionales, que desafían e introducen incertidumbre en las actividades 
de otros (Tilly; Tarrow). En este trabajo se parte de esta definición considerando prácticas que no necesariamente se encuentran por fuera de los canales institucionales, lo cual resulta útil para considerar una variedad de acciones "tradicionales" y "alternativas", "convencionales" y "no convencionales" (Gadea; Norris) que los movimientos sociales contemporáneos realizan.

Desde abril de 2018, en Nicaragua, el repertorio de acciones colectivas ha venido incluyendo múltiples formas de resistencia y movilización social. Entre las más recurrentes, según el monitoreo de Protestas, ${ }^{4}$ se encuentran: los mítines o concentraciones, las marchas, las reuniones con autoridades, las asambleas, las huelgas de hambre, las declaraciones púbicas y los bloqueos, barricadas o tranques. En este conjunto de acciones, la toma simbólica y el resguardo de diferentes universidades, tales como la Universidad Nacional, la Universidad Agraria, la Universidad de Ingeniería y la Universidad Politécnica, ejemplifican el protagonismo estudiantil.

En estas protestas también ha sido clave el componente cultural-artístico, acciones también llamadas "microacciones" o "piquetes", por las personas activistas, tal como lo expresa Victoria, activista de 28 años.

El apoyo del pueblo siempre [ha estado presente]... ya no tanto en las calles en marchas, sino con pequeños piquetes: expresiones como tirar de manera masiva globos en azul y blanco que es la bandera que cobija nuestra nación; tirar papeletas en una madrugada donde no hay policías y no hay gente investigándote, y salir corriendo; llegar y colgar una manta que diga cosas alusivas a la represión que estamos viviendo y salir corriendo: cosas chiquitas en donde no te puedes quedar por mucho tiempo porque igual el gobierno llegaba de manera rápido con sus patrullas y boom te capturaban te hacian de todo y si no te encarcelaban por lo menos te daban una buena golpiza en el chipote o [te llevaban] a alguna de las estaciones policiales (Victoria, comunicación personal, junio de 2019).

Especial atención merece también el tema de los "tranques" o barricadas. Estos han sido utilizados, tradicionalmente, según las narraciones de los activistas, como medida de contención de la protesta por el gobierno, con el objetivo de que el movimiento campesino no consiguiera llegar a Managua a protestar. Sin embargo, en el marco de las protestas de 2018, el pueblo decidió organizarse y poner "tranques" como forma de protesta contra la violencia que se estaba ejerciendo contra los estudiantes. De esta forma, en diferentes regiones, la población los apoyó para que no entraran vehículos de la policía, paralizando diferentes rutas de transporte usada para fines comerciales.

El uso de medios tecnológicos de comunicación, tradicionales y novedosos, ha sido importante desde la primera protesta y las ulteriores acciones represivas que se desplegaron en contra de los manifestantes. Las redes sociales abrieron otras posibilidades de comunicación para la difusión de las movilizaciones. El Internet ha sido utilizado 
para trasmitir pronunciamientos, testimonios de la represión que han experimentado, información sobre los presos políticos, campañas informativas y convocatorias para generar nuevas acciones colectivas.

Se viralizó en todo el país, por todos los medios radiales, televisivos y con las aplicaciones de los teléfonos también, entonces los estudiantes salieron a defender, a los abuelos, de la tercera edad, y pué, reventó el estallido por Nicaragua (Victoria, comunicación personal, junio de 2019).

Continúo con la televisión local, programas de radio, programas nacionales donde se me invitaba a hablar del tema. Ya no como comunidad LGBT [sic], sino como mi participación política dentro de la dinámica. En tanto cómo nos sentíamos los chavalos. Que no es lo mismo ser un influencer de cómo pintarse las uñas a temas políticos, teníamos que ser súper creativos para llegarle a una juventud en la cual muchos decían que como somos los milleniales, muy tecnológicos y todo, en el celular -aparte de las estrategias del gobierno para mantenernos despistados, con los parques WiFi, por ejemplo-. Todo el mundo pegado en redes sociales, jugando pero no se metían en temas políticos. Incluso muchos de los que se movilizaron ahorita se están planteando "en qué momento me metí en esto", ¿me entendés? (Bayardo, comunicación personal, septiembre de 2018).

La "viralización" o la masiva divulgación de información que realizaron los activistas les permitió contrarrestar la información ofrecida por la televisión y otros medios, generalmente reproductores del discurso oficial. Esto provocó el descontento de sectores que incluso no se había movilizado anteriormente y la participación de jóvenes que tuvieron una especie de iniciación política durante estas jornadas de protestas, a quienes Bayardo denomina "activistas emergentes", como fue el caso de Solange, activista de 21 años.

Yo entré de manera... individual se le puede llamar, auto convocada, yo iba sola cuando salía de mi trabajo. A veces le decía a mi jefa, ya vengo y me iba a marchar sólita y a los plantones también, yo ya entre al movimiento como el 13 de mayo, yo de ahí comencé a entrar al movimiento, me pidieron primero un favor-como que iquieres servirles comida a los muchachos del tranque?, y yo, pues, obvio lo iba a hacer, no iba a decir que no-y ahi comencé pues en el movimiento y ahi me quede, $y$ ahi estoy, $y$ ahí sigo activa siempre en el movimiento de Matagalpa (Solange, comunicación personal, junio de 2019).

Por su parte, un tema controvertido es el uso de armas caseras y armas de alto calibre entre los manifestantes que se encontraban en los tranques, independientemente de que se opte usarlas o no. Desde la parte oficial, tanto las protestas y el uso de armas fueron catalogados como parte de un intento de un golpe de Estado orquestado por los Estados Unidos; para los activistas, el uso de armas se entiende como una 
forma más de resistencia y defensa necesaria ante la represión gubernamental. Las palabras de Ximena ilustran esta última postura.

Hay una raíz de violencia pues venimos de conflictos armados que no han sido resueltos, tratados psicosocialmente, entonces muchas personas que vienen de la guerra pasada han despertado en sus cuerpos este modo de alerta y lo primero que piensan es "hay que armarse, hay que combatir" pues es lo que han aprendido. La revolución sandinista se logró por las armas, con la muerte, entonces como fue un éxito ahora muchos lo ven como una posible vía... Mi postura es pacífica, abierta al diálogo. Muchas de mis redes apuestan por una vía pacífica, por el diálogo, no más impunidad. Apuesto por la protesta pacifica que nos ha identificado, bien genuina, bien nica, con globos por ejemplo, con baile, en las trinchera se baila, se toma, los presos politicos son activistas; son personas, salen sonriendo, estoy seguro que la vía correcta no es la violencia pero está enraizada en nosotros esta manera heroica del hombre que viene como súper héroe a través de la fuerza a defender un público... Quienes salimos perdiendo es la gente más pobre que pone los cuerpos (Ximena, comunicación personal, septiembre de 2018).

El relato de Ximena resulta relevante, dado que expresa, por un lado, la coexistencia de formas pacíficas, lúdicas y artísticas de lucha con repertorios tradicionales de activismo que incluyen la violencia. En conjunto, son elementos que en una reflexión detenida abonan a la comprensión de los cambios en la cultura política de las personas activistas en Nicaragua. Se trata de un tema que excede el interés exploratorio de este trabajo y que queda abierto a futuras reflexiones académicas y activistas, porque incluso en el marco de las jornadas de protesta, al menos durante la irrupción, no ha podido discutirse al respecto, a decir de Bayardo.

No no, nunca hubo espacio [para la discusión]. [El movimiento nos tomó] como carreta en bajada, decimos nosotros, los activistas de siempre tratando de aprovechar a esos activistas emergentes que quieren planear y hablar para cómo hacer las cosas, nosotros entramos en cada uno de los departamentos tratando de recordarles que existen otras maneras cívicas y pacificas de hacer las cosas. Pero como nos han creado en Nicaragua de que toda liberación debe ser por medio de armas lo primero que hablaban es que "a quién le vamos a pedir la plata para las armas". Todo es armas. De Matagalpa también me muevo porque un dirigente era también agresivo y me exige que me retire porque lo tengo harto diciéndole "no hagas esto" "no secuestrés a este". Se puso de acuerdo con los demás y me dijeron "Bayardo salite, esta no es tu lucha, no sentís que es tu lucha" (Bayardo, comunicación personal, septiembre de 2018).

\section{Represión y exilio}

Como ya se ha planteado en este texto, la represión ejercida a la oposición política no es novedosa. Desde el 19 de abril, sin embargo, la violencia de Estado se ha incrementado exponencialmente a través del uso desproporcionado de la fuerza policíaca, 
las ejecuciones extrajudiciales, las desapariciones forzadas, las detenciones arbitrarias e ilegales, los casos de tortura, la violencia sexual en centros de detención, las obstrucciones a la atención médica y la criminalización de los defensores de los derechos humanos, los periodistas y los manifestantes. Entre las principales violaciones a los derechos civiles y políticos de los nicaragüenses se incluyen la violación a los derechos a la vida, la asociación, la concentración, la movilización y la manifestación pública, la petición y la denuncia, la libertad individual, la libertad de conciencia, el pensamiento en público y privado, no ser sometido de manera arbitraria y al debido proceso, y a elegir y ser electo.

Diferentes informes entre 2018 y 2019 dan cuenta de la magnitud de este problema. Cabe mencionar algunos de estos: "Human rights violations and abuses in the context of protests in Nicaragua", de la Oficina del Alto Comisionado de Derechos Humanos de Naciones Unidas (Naciones Unidas para los Derechos Humanos, 2018); "Actualización sobre Nicaragua en la 41 sesión del Consejo de Derechos Humanos", del Alto Comisionado de Derechos Humanos de Naciones Unidas (Naciones Unidas para los Derechos Humanos, 2019); “Disparar a matar. Estrategias de represión de la protesta social en Nicaragua", de Amnistía Internacional (AI); "Informe Graves violaciones a los derechos humanos en el marco de las protestas sociales en Nicaragua", de la Comisión Interamericana de Derechos Humanos (CIDH), “Nicaragua”, del Grupo Interdisciplinario de Expertos Independientes (GIEI), "Brutal represión. Torturas, tratos crueles y juicios fraudulentos contra manifestantes y opositores en Nicaragua", de Human Rights Watch, y "Situación de Derechos Humanos en Nicaragua”, elaborado por la Asociación Hagamos Democracia (Hademos).

No obstante que el gobierno ha negado la participación de grupos policíacos del Estado en la violencia ejercida sobre los manifestantes, su versión de los hechos es insostenible si se consideran los testimonios recopilados en dichas indagaciones. El 18 de abril, día en que se realizó la primera protesta, manifestantes de Matagalpa y Managua fueron víctimas de intimidaciones y agresiones por parte de los trabajadores del INSS, integrantes de la Unión de Estudiantes de Nicaragua (UNEN), grupos de encapuchados denominados "turberos", personas que portaban camisetas de la Juventud Sandinista y cuerpos policíacos. Al día siguiente, el 19 de abril, murió el primer estudiante universitario, lo cual en buena medida detonó el Movimiento 19 de abril en diferentes lugares del país.

Tras la represión desplegada por el Estado entre mayo y julio, se dieron los primeros esfuerzos por solucionar el conflicto a través del diálogo. Desde entonces ha sido importante el llamado realizado por la Iglesia católica y el sector empresarial al gobierno de Ortega para buscar una salida política. Sin embargo, la continuidad de las estrategias represivas fue anulando las posibilidades del diálogo abierto entre el 15 de junio y el 9 de julio del 2018. 
El 10 de julio el gobierno desplegó la "operación limpieza" con el objetivo de recuperar el control de los espacios públicos. Como parte de estas acciones se desmantelaron todos los tranques con un saldo de decenas de personas asesinadas y cientos más arrestadas y torturadas. En este mismo mes se sumaron diferentes estrategias represivas entre las que se incluía la aprobación de leyes que podrían suelen ser utilizadas para equiparar las acciones de protesta con acciones terroristas.

Al ser levantados todos los tranques a punta de balas, venia la "última limpia", como le llamo el gobierno a desalojar la universidad, y fue ahi donde se dio el ataque que duro más, más de una docena de horas pasaron, toda una noche en vela, si gustas podes ir a la divina misericordia que es la parroquia que está más cerca de la universidad donde todavía están los huecos donde tiraban las balas, esa noticia fue internacionalmente conocida, ahora pues lo que se vive en Nicaragua después de la brutal masacre fueron las capturas masivas mediante el tendido de investigación que tiene el gobierno con su gabinete de poder ciudadano, con los CPC que son los comités de poder ciudadano (Victoria, comunicación personal, junio de 2019).

El caso de Bayardo, activista de 28 años, es ilustrativo de las centenas de detenciones arbitrarias. Él se dirigía en autobús de Nicaragua a Costa Rica, en la frontera de Peñas Blancas; posteriormente, fue trasladado, primero a prisiones de Managua, y posteriormente a Matagalpa. Estuvo preso alrededor de diez días, durante este tiempo no le fue permitido realizar llamadas telefónicas, fue privado de alimentos que sus familiares le llevaban cuando se enteraron de su ubicación, fue objeto de violencia física y psicológica, y fue testigo de la manera en que se golpeaba y vilipendiaba a otros jóvenes detenidos. En entrevista, Bayardo narró las condiciones de su encarcelamiento en el Chipote, prisión ligada capítulos represivos durante la dictadura somocista.

En la cárcel del Chipote me infecté de un hongo en todo el cuerpo. Las celdas eran súper sucias, era un hoyo solamente para poder hacer tus necesidades... te mantenías en bóxer o desnudo en la celda. En el día Managua es súper caliente, y las celdas en el día eran un horno, costaba respirar, y por las noches se enfriaban extrañamente. Eso era súper frio. Eran paredes de concreto rellenas de hierro. La habitación era de 2 por 2 metros, y habia 4 personas. Para mí que es intencional que esté ese hongo porque desde el primer momento que yo puse el pie, me comenzó a arder, a corroer el pie, fue impresionante, fueron 4 días para salir completamente llagados mis pies (Bayardo, comunicación personal, septiembre de 2018).

Otros cientos de detenidos no fueron liberados de manera rápida, quizás porque sus casos no fueron lo suficientemente mediatizados y no existió la suficiente presión externa. Victoria y Solange, dos activistas entrevistadas, estuvieron alrededor de 9 meses detenidas; hubo personas que estuvieron presas por más de 1 año. Las condiciones del encierro son similares y las formas de tortura psicológica y física son referidas también en los casos entrevistados. 
Las alergias, las infecciones las enfermedades, los hongos, de todo pasamos ahi, a los tres o cuatro dias que estabas ahi, ya estabas con roncha, de todo, entonces... el tanque de abastecimiento de aguas negras colapsó (Victoria, comunicación personal, junio de 2019).

Para sacar a la Irlanda, yo fui una de las que fue golpeada yo tuve un bravaje (sic) en todo mi cuerpo, me rajaron el labio, tenía aruños, ahi fue donde me fracturaron la columna, porque de ahí me comenzó a dar mucho dolor ahí ese día me golpearon horriblemente, no solo a mí, a todas las que estábamos allá adentro, éramos 8, para poder sacar a ella la querían sacar y no sabíamos porque, y como era de noche y no sabíamos para donde la llevaban, entonces nos defendíamos entre todas porque como estaba la situación, que te dan por desaparecido o algo, y entonces nosotros evitábamos eso (Solange, comunicación personal, junio de 2019).

Un listado fechado el 18 de marzo de 2019 permite dimensionar la posibilidad abierta de ser detenido o desaparecido. Este contiene 802 nombres de personas que han sido reportadas como presas políticas o desaparecidas entre abril de 2018 y marzo de 2019. En ese sentido, julio de 2018 es el mes en que más detenciones fueron realizadas; estas fueron llevadas a cabo principalmente en Managua, Masaya, Carazo, León y Matagalpa, tal como aparece ilustrado en la Figura 2. 


\section{E T E N C I O N E S A R B I T RARIAS}
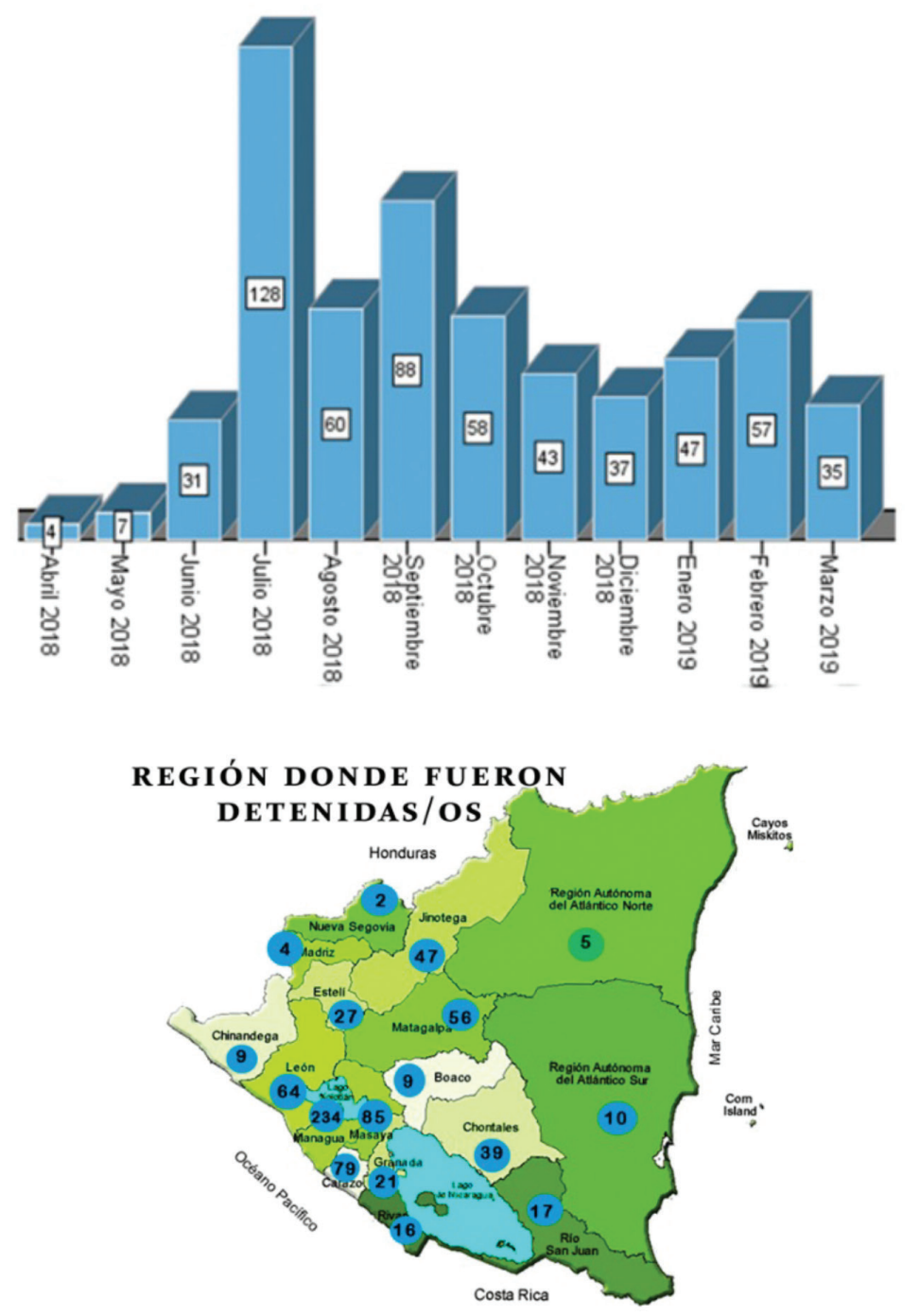

Fuente: Elaboración propia a partir del Comité de Liberación de Presos Políticos (19 de marzo de 2019).

Después de que Ortega destruyera de forma violenta los tranques o barricadas, se ha dado paso a otra etapa represiva apoyada en el poder de los medios de comunicación, la violencia policíaca, la aprobación de la "ley antiterrorista" y la manipulación 
del sistema judicial. La aprobación de la Ley N. 977 ha sido una de las acciones en que se basan las estrategias represivas, dificultando la situación jurídica de los detenidos. En su artículo 44, manda reformar los artículos 394 y 395 de la Ley 641 o Código Penal de la República de Nicaragua, lo cual modifica la definición de terrorismo y financiamiento al terrorismo al utilizar tipos penales abiertos que dejan al criterio absoluto del juzgador la interpretación de estos (Hademos).

Alberto Novoa, abogado y exprocurador general de la República, evidenció la arbitrariedad y ambigüedad de esta ley, al cuestionar:

¿Quién califica a una organización de terrorista, el gobierno? Recientemente han sido detenidas como colaboradoras del proyecto terrorista personas que lanzaron a las calles globos azules y blancos... ¿Y qué significa alterar el orden constitucional? ¿Pedirle la renuncia a Ortega, pedir elecciones anticipadas? ¿El que pide eso es terrorista? ¿El que pide la derogación de la ley canalera, la ley 840 es terrorista? Si analizamos lo que dice esa ley nos damos cuenta que buena parte de nuestras acciones ejerciendo derechos pueden caer en el ámbito penal de "terrorismo" y es a ese abuso a lo que estamos hoy expuestos (Novoa 5).

El caso de Yooselín es un ejemplo de la instrumentalización de la Ley 977. Yooselín, de 22 años, es una estudiante de medicina que apoyó la manifestación de las personas de la tercera edad en contra de las reformas y, posteriormente se unió a las protestas, incluso cuando diariamente había manifestantes heridos.

Manifestarse por lo mismo, para que mi hijo gozara de una libertad, para que pudiéramos seguir gozando de una libertad, por ver la injusticia que se hizo cuando comenzaron las protestas, de que se cerraron los hospitales para todos los heridos, si ibas a los hospitales, saliendo ibas para el Chipote, donde estuve por tres días... Los estudiantes fuimos médicos reales, sacamos balas, curamos heridas en espacios tan pequeños y con pocas cosas. A mi me acusaron de terrorismo. Estábamos intentando rescatar a una familia, que por no permitir que subieran francotiradores arriba, los quemaron. Por querer ayudar ese día, me llevaron al Chipote y después de dos dias me pasaron al Sistema Penitenciario (Citado en La Sexta).

En suma, los testimonios exponen que los opositores han sido reprimidos por la Policía Nacional, fuerzas antimotines y grupos parapoliciales; han sido secuestrados, ilegalmente y detenidos sin orden; no han sido presentados al juez en las 48 horas posteriores; y han recibido malos tratos, torturas e ilegalidades (Comisión Interamericana de Derechos Humanos). Asimismo, personas de organizaciones civiles, institutos de salud o simpatizantes del movimiento fueron posteriormente víctimas de represalias, tales como amenazas, despidos, o bien, fueron obligadas al exilio.

Por lo anterior, miles de jóvenes nicaragüenses han optado por el exilio para evitar el costo de la represión. Entre los principales destinos a los que las y los jóvenes se dirigieron se encuentra Costa Rica, un territorio que históricamente ha sido espacio 
de intercambio y desplazamiento de nicaragüenses, pero también diferentes países de América Latina y Europa. Harvin, de 29 años, es uno de los miles de jóvenes exiliados en Costa Rica. Se sumó a las protestas, siendo parte de la Plataforma Nacional Juvenil y del Movimiento Autónomo 18 de abril. Como parte de sus acciones, buscó apoyar a opositores que iban a ser capturados acusados de terroristas, exigiendo el respeto de los derechos humanos. Esto le valió para que fuera identificado y perseguido por el gobierno, una suerte compartida con muchos jóvenes que participaron en alguna de las protestas. Salir del país no estaba entre sus planes, pero la violencia de Estado lo obligó a optar por el exilio.

No lo habia pensado, pero la familia me dijo que no llegara a mi casa porque andaban preguntando por mí. Vi que no podía ver a mi familia y que tampoco podía estar en un país donde la vida no valía nada y tampoco hay posibilidad de seguir trabajando, por todo lo que estaba pasando también, y ya no podias seguir encerrado en algún lugar en Nicaragua sabiendo que en cualquier momento podían atentar contra tu vida. Lo que hice fue decidir que sí lo que iba a hacer, siempre apoyando la lucha. Decidi optar por una maestría en derechos humanos [en Costa Rica]. Vi la necesidad de hace investigación para que en Nicaragua se demande todo lo que el gobierno estaba haciendo al pueblo (Harvin, comunicación personal, septiembre de 2018).

Otro caso es el de Ximena, activista ecofeminista de 23 años, quien decidió salir del país por los riesgos de la misma escalada de violencia. Participante de diferentes protestas en los últimos años e inmersa en la organización de acciones colectivas de tipo cultural y artísticas, manifestó haber experimentado la euforia de la movilización social y un compromiso con el movimiento social abierto en abril de este año. Sin embargo, la cercanía de la violencia que ya había alcanzado a sus amigos cercanos y conocidos, quienes fueron heridos y asesinados, la orilló a tomar la decisión de salir de su país por primera vez.

Fue una decisión difícil, pero pensé que era necesario salir porque después se iba a poner más difícil. Hay amigos que ya no lograron salir legalmente. Se han venido "mojados", ilegalmente, porque ya ha sido imposible. Vivo en el exilio, nunca había salido del país, habian intentos de ir a eventos y congresos... jamás me imaginé que la primera vez que salí de mi país iba a salir exiliada, es duro ver los contrastes de cómo se vive en otro país (Ximena, comunicación personal, septiembre del 2018).

Los flujos de nicaragüenses en Costa Rica son difíciles de contabilizar con precisión, pero según datos de la Dirección General de Migración y Extranjería (DGME) (citado en Contreras), desde 2001 hasta junio de 2018 se contabilizaron más de 23 mil solicitudes de refugio de nicaragüenses; más de 22 mil de estas solicitudes son realizadas en el marco de las protestas. Según datos de ACNUR, hasta abril de 2019, alrededor de 62 mil nicaragüenses han salido del país en busca refugio, de los cuales unos 55 mil han ido a Costa Rica. 
Entre los desplazados se encuentran estudiantes, antiguos funcionarios, líderes de la oposición, periodistas, médicos, defensores de derechos humanos y agricultores. Muchas de estas personas han atravesado la frontera de manera irregular, expuestos a altas temperaturas, la humedad y otros riesgos. Estos desplazamientos tampoco cubren el perfil que tradicionalmente había arribado a Costa Rica bajo la condición de refugio -mujeres de origen rural-; ahora se trata principalmente de jóvenes con estudios técnicos o con estudios profesionales truncos, a decir de Jenyel Contreras (Red Politik).

Esto ha llevado a que el gobierno de Costa Rica apruebe -con ayuda del Alto Comisionado de las Naciones Unidas para los Refugiados- una serie de políticas para acoger a los refugiados y perseguidos políticos de Ortega. El 23 de agosto de 2018 se creó un protocolo para el manejo de atención integral de flujos migratorios extraordinarios en el cual participan 30 instituciones públicas y 7 organizaciones internacionales. Entre los ejes de acción se encuentran: garantizar la seguridad pública, laboral, sanitaria y educativa; y reforzar los controles fronterizos, mayor coordinación entre diputados, alcaldías, iglesias y sociedad civil (Elpaís.cr).

El crecimiento exponencial de tales exilios potenció el sentimiento xenófobo de costarricenses que organizaron una manifestación en el centro de San José. Así, el 18 de agosto, cientos de personas que portaban símbolos nazis y armas blancas lanzaron consignas en contra de la población nicaragüense en la Plaza La Merced y otros espacios de San José. Estas manifestaciones terminaron en disturbios y 44 personas fueron detenidas. Días más tarde, se suscitaron pronunciamientos y acciones antixenofóbicos de diferentes actores políticos y sociales que reivindicaron el vínculo histórico de solidaridad entre Nicaragua y Costa Rica.

El desplazamiento de estas personas plantea nuevos y numerosos desafíos. A las personas jóvenes recién llegadas se les coloca en una condición de vulnerabilidad, por los tiempos tan largos que demoran en dar respuesta a las solicitudes de refugio y la imposibilidad de laborar que esto conlleva, considerando particularmente que más del 90 por ciento de las solicitudes de refugio habían sido rechazadas (Contreras).

Al gobierno le corresponde desplegar acciones para cumplir con los compromisos contraídos y dar respuesta a las demandas básicas de vivienda, salud, atención psicosocial y educación de los recién llegados. Se trata de una tarea que no es sencilla porque es probable que muchos sean las personas jóvenes que aspirarán a matricularse y concluir una licenciatura en la universidad pública y porque recientemente Costa Rica experimenta una crisis fiscal que ha dado motivos a reformas y protestas entre diferentes sectores sociales. ${ }^{5}$ Desde el exilio, las personas jóvenes esperan que las condiciones en Nicaragua mejoren para poder volver.

No veo Costa Rica como destino para vivir, temporalmente estudiaré y trabajaré pero no veo a CR como un país destino, porque en Nicaragua tengo mi familia, mi círculo social y hay muchas cosas que se pueden crear y hacer politicamente en Nicaragua, restablecer la democracia, evitar la violencia que se viene haciendo (Harvin, comunicación personal, septiembre de 2018). 
Prefiero estar en Costa Rica por el momento, avanzar en la universidad, parece que mi universidad va abrir clases virtuales y quiero terminar de estudiar, conseguir un empleo, enviar dinero a mi familia que también se ha visto afectada, y también seguir la lucha, visibilizándola. Considero que la presión internacional es clave, sin duda no resuelve los problemas, pero quiero seguir haciendo lo que hemos hecho: aprovechar espacios que se nos abren y tratar de organizarnos y articularnos mejor (Ximena, comunicación personal, septiembre de 2018).

Desde el exilio en Costa Rica, también muchos jóvenes continúan participando en la lucha. Bayardo, Harvin y Ximena saben muy bien que las redes han sido fundamentales para que ellos puedan conseguir apoyo elemental en su estancia en este país, por lo cual buscan dar continuidad y fortalecer las de redes de solidaridad entre nicaragüenses, coadyuvando, entre otras cosas, para que las personas que se encuentran en albergues bajo condiciones precarias puedan acceder a servicios de educación, salud y refugio, pero también en materia de prevención de problemas latentes como son la trata de personas, la explotación laboral y la militarización de las personas jóvenes.

Aunado a estos problemas Ovalle, activista de 28 años que forma parte de la Articulación de Movimientos Sociales y que ha estado desde la sociedad civil apoyando las redes de apoyo a exiliados, señala otras particularidades del exilio a tener en cuenta. Por un lado, indica que hay investigaciones que apuntan a que la mayoría de los exiliados no desean regresar a Nicaragua; por otro, plantea que es importante no soslayar que muchos de estos exiliados experimentan la adaptación del ámbito rural al urbano lo que genera otros retos; $y$, finalmente que no se puede considerar a todos los exiliados como un bloque homogéneo de personas, pues existen diferentes posturas ideológicas que hacen complicada su articulación.

En todo caso, el papel de las organizaciones de la sociedad civil que configuran las redes de apoyo a los exiliados de Costa Rica es fundamental pero limitado. Resulta primordial, en tanto que se calculan más de 100 organizaciones, a decir de Ovalle, constituyéndose como un espacio que posibilita acciones y organización que no son viables en estos momentos en Nicaragua. Sin embargo, es limitado porque, como Contreras argumenta, mucho del apoyo que se ofrece es principalmente en los primeros meses, y, posteriormente, no existe un seguimiento, además, porque los derechos sociales elementales están condicionados a la obtención de un empleo formal que a su vez está vinculada a la condición de refugio.

\section{La controversial Ley de Amnistía}

Desde febrero del 2019, el gobierno de Daniel Ortega ha liberado gradualmente a la mayoría las personas que fueron detenidas, como resultado de la segunda jornada de diálogos entre el Gobierno y la Alianza Cívica por la Justicia y la Democracia, 
de donde surgieron dos acuerdos: la liberación de cientos de presos políticos y el compromiso de respetar los derechos fundamentales de los ciudadanos. Estos acuerdos se han dado en un marco de profunda desconfianza entre las partes, en el contexto de una economía que ha venido colapsando ${ }^{6}$ y ante el deseo del Gobierno de eludir y suspender las sanciones internacionales.

Entre las liberaciones de 2019, se encuentra el caso de Victoria, joven mujer trans, que era estudiante de Gestión de la Información de la Universidad Autónoma de Nicaragua (UNAN), activista defensora de los derechos de la comunidad LGBTTTI, quien formaba parte de la Coordinadora Universitaria por la Democracia y la Justicia (CUDJ). Victoria fue liberada después de 9 meses de estar encarcelada en el Sistema Penitenciario La Modelo, acusada de terrorismo, homicidio, secuestro, robo con intimidación y amenaza de muerte. En todo este tiempo ha dado a conocer en diferentes medios la represión y las torturas a las que ha sido sometida y, en entrevista, expresó sus intenciones de seguir en resistencia.

Estamos entrando en una segunda fase, ya están siendo liberados los presos políticos, pero después de eso, ¿qué sigue?, ¿qué vamos a hacer?, seguimos trabajando en función de terminar de organizarnos, de unir a todos los frentes y los sectores sociales para trabajar en un mismo plan para sacar a Ortega y el imperio que ha construido en su beneficio, seguimos trabajando para nuestra seguridad. No tenemos miedo de volver presos. A nivel jurídico me voy a defender con la [Ley de] Amnistía, pero no nos pueden pedir que olvidemos, tenemos más de 500 muertos, desaparecidos, madres que siguen en luto, gente en el exilio, tenemos pruebas de todo, ¿cómo vas a querer que hagamos borrón y cuenta nueva? (Victoria, comunicación personal, 11 de junio de 2019).

En este escenario, la liberación de presos parece ser una muestra de la necesidad del gobierno de Daniel Ortega para abrir paso a una posible solución política al conflicto. Sin embargo, estas liberaciones no se han caracterizado, según grupos opositores, por ofrecer la plena libertad a las personas excarceladas, prevaleciendo la falta de transparencia y la certeza legal para estas.

El 8 de junio de 2019, la Asamblea Nacional de Nicaragua aprobó la Ley de Amnistía, la cual absuelve a todas las personas involucradas en crímenes en relación con los acontecimientos del 2018. La promulgación de esta ley permitió que el pasado 11 de junio se liberara a más de 50 personas, entre los que se encuentran algunas de las principales figuras de las protestas, lo cual fue motivo de celebración en diferentes partes de Nicaragua.

Como Victoria, otros activistas recién liberados se han expresado, a través de diferentes medios, que están con toda la disposición de continuar movilizados y articulados para buscar transformar la realidad sociopolítica de su país y tienen claro que estas excarcelaciones no son suficientes para volver a la estabilidad económica y 
el clima de paz. Las personas jóvenes movilizadas saben que será un proceso complicado y que se abren numerosos desafíos para los diferentes actores involucrados.

Con respecto a la Ley de Amnistía de Presos Políticos existen diferentes preocupaciones y críticas. Por un lado, se cuestiona la cláusula de la "no reincidencia" que vulnera los derechos de expresión de los activistas, quienes se reivindican como presos políticos y no se reconocen como culpables de ningún delito "contra la seguridad común y tranquilidad pública" o "responsables de golpe de Estado fallido" como el gobierno los define; por otro lado, resulta preocupante la impunidad que permitiría esta Ley para personas potencialmente responsables de graves violaciones a los derechos humanos en el contexto de las protestas (ACNUDH).

De tal suerte, el gobierno de Ortega, con la liberación de la mayoría de las personas detenidas, ha enviado un mensaje de buena voluntad hacia los críticos nacionales y extranjeros. Sin embargo, al 18 de junio, fecha en que se cumplieron los 90 días de plazo para la liberación de todos los detenidos en el marco de las protestas, no se habían liberado a todos estos. Según la oposición, hacia el 20 de junio de 2019 permanecían 86 personas detenidas, por lo cual el gobierno no ha cumplido con los números y tampoco con los procedimientos (La Prensa Latina).

Asimismo, siguen sin cumplirse los acuerdos referentes al tema de los derechos ciudadanos. Estos últimos son fundamentales, en tanto que contemplan: el debido proceso legal, los derechos políticos y económicos, la seguridad, autonomía universitaria, la libertad de expresión y el derecho a retornar de los nicaragüenses exiliados, así como un llamado a las fuerzas de seguridad para la desarticulación de los grupos armados ilegales y el cumplimiento con las normas internacionales sobre el uso de la fuerza.

En suma, el gobierno de Ortega hacia la mitad del 2019 cedió parcialmente ante las presiones internas y externas, evitando ser objeto de nuevas sanciones de países extranjeros y organismos internacionales, específicamente la Unión Europea (UE), Estados Unidos (EE. UU.) y la Organización de los Estados Americanos (OEA). Sin embargo, el contexto que se vive hoy en Nicaragua continúa siendo inestable: portavoces de la Alianza Cívica por la Justicia y la Democracia dijeron que esperan que el gobierno cambie de opinión y que se libere a las personas que continúan detenidas. Por su parte, el Gobierno ha advertido que ya se realizó plenamente la liberación de los nombres en las listas consensuadas entre la Alianza Cívica, el gobierno y el Comité Internacional de la Cruz Roja (CICR).

Entre los activistas, sin embargo, prevalece el ímpetu de seguir movilizados y lo hacen de maneras diversas. Algunos participan con acciones de tipo cultural, performativo o soterradas, con "microacciones" o "piquetes" como algunos las denominan, procurando disminuir el costo de la represión. Mientras que otros jóvenes exiliados siguen movilizados en caravanas por América Latina y Europa, buscando visibilizar la situación de Nicaragua y promoviendo el apoyo de la comunidad internacional. 


\section{Reflexión final}

El gobierno de Daniel Ortega ha optado desde hace algunos años por el despliegue de estrategias represivas con el objetivo de desarticular las movilizaciones sociales de campesinos, mujeres y otros grupos sociales, por lo cual no sorprende que en 2018 haya optado de nuevo por esta vía. Durante este año, lejos de que las acciones represivas hayan desmovilizado a los manifestantes deslegitimando al movimiento, los grupos opositores fueron sumando simpatizantes y sumando nuevos actores sociales a su lucha, en desmedro de la legitimidad del gobierno de Ortega.

La represión, por su parte, fue agudizándose, diversificándose en sus formas y extendiéndose a los simpatizantes del movimiento, lo cual derivó en una crisis de derechos humanos inaudita en la historia democrática de Nicaragua. El exilio de jóvenes nicaragüenses fue uno de los efectos de estas acciones represivas. Por sus dimensiones cuantitativas y por las condiciones de vulnerabilidad social en las cuales se sitúan las personas jóvenes exiliadas en los lugares a los que arriban, estos desplazamientos implican una serie de desafíos para las y los jóvenes que han llegado al país y para las instituciones del Estado costarricense.

En este trabajo se ha analizado la forma en que se relacionan los procesos de movilización social, de represión y de exilio experimentado por jóvenes nicaragüenses en Costa Rica. Las personas jóvenes entrevistadas, pese a sus biografías particulares, comparten un posicionamiento crítico ante el gobierno sandinista encabezado por Daniel Ortega, pero no así sobre los ideales sandinistas que se reivindicaron en la revolución. De ahí que el gobierno de Ortega les represente la traición a esos ideales y la expresión tiránica de valores autoritarios y dictatoriales.

Más allá de los resultados inmediatos de las movilizaciones, es importante considerar la importancia de las protestas iniciadas en 2018, por la impronta que deja como marca generacional, expresada en las experiencias concretas de politización y participación de jóvenes activistas. Es a través de estas experiencias individuales y colectivas activistas que puede identificarse la construcción de "unidades generacionales políticas" que revelan continuidades y rupturas expresadas, por ejemplo, en lo que significa ser oposición hoy en día en Nicaragua y el papel de "cultura de las armas" y la violencia como parte del repertorio de acciones contempladas para la lucha social.

Después de quince meses de haber comenzado las movilizaciones de 2018, cuando se hace un corte analítico en este trabajo prevalece la incertidumbre. Las diferentes vertientes de la oposición tienen de frente el reto de continuar articulados y buscar una posición común de frente a un gobierno que continúa ejerciendo acciones represivas, manteniendo diferentes frentes de disputa abiertos con la oposición, los sectores empresariales y la comunidad internacional. Ante la complejidad del escenario político nicaragüense, no se avizoran a corto plazo condiciones que permitan regresar a las personas jóvenes nicaragüenses exiliadas. 
Este trabajo y la conclusión anterior tienen un límite evidente. La juventud sandinista y otros jóvenes que conforman los grupos de choque al servicio del gobierno de Ortega también revelan otras unidades generacionales, otras formas de ser joven en Nicaragua, a pesar de coexistir en un mismo periodo histórico, lo cual abre la posibilidad y necesidad de futuros análisis que permitirían comprender la pluralidad de condiciones estructurales y simbólicas en las cuales se está configurando la juventud nicaragüense.

\section{Notas}

$1 \quad$ El trabajo de transcripción de tres entrevistas y la sistematización de la información de la Lista Preliminar de Desaparecidos, Presas y Presos Políticos estuvo a cargo del Lic. Alberto Vázquez.

El Observatorio de las Democracias: Sur de México y Centroamérica (ODEMCA) es un grupo de investigación con sede en el Centro de Estudios Superiores de México y Centroamérica (CESMECA), de la Universidad de Ciencias y Artes de Chiapas (UNICACH). Para más información puede visitarse https://observatoriodelasdemocracias.com.mx/

El Padrón electoral se calculó en 3.8 millones de personas, de las cuales 1.4 pertenecen a Managua. Participaron 16 partidos, de los cuales 4 compitieron solos y los demás en 2 alianzas, figurando en las boletas electorales de la siguiente manera: el Frente Sandinista de Liberación Nacional (FSLN), el Partido Liberal Independiente (PLI), el Partido Liberal Constitucionalista (PLC), la Alianza Liberal Nicaragüense (ALN), el Partido Conservador (PC), la Alianza Por la República (APRE) y, en la costa Caribe se acreditó una opción más, el partido indígena Yapti Tasba Masraka Nanih Asla Takanka (Yatama).

Protestas es una base de datos sobre protesta social en Costa Rica, Nicaragua y El Salvador, producida de acuerdo con el seguimiento de las acciones colectivas reportadas en medios de comunicación escrita. Este proyecto tiene sede en el Instituto de Investigaciones Sociales de la Universidad de Costa Rica. Para más información, puede consultarse https://protestas.iis.ucr.ac.cr/

La mayoría de estos desplazamientos comenzaron semanas antes de que diera comienzo la serie de protestas en contra del "combo fiscal" promovido por el ejecutivo costarricense, hecho que generó amplias movilizaciones sociales en este país, después de más de una década en que no se presentaba tal disgusto popular. Esta ola de movilizaciones abierta en Costa Rica fue eliminando gradualmente de las discusiones el tema de los desplazados.

La economía de Nicaragua ha venido colapsando y se encuentra en recesión. Según datos del Banco Mundial, la economía se contrajo un 3.8 por ciento en 2018 y se contraería a -5 por ciento en 2019. Para más información, puede consultarse https://www.bancomundial.org/es/ country/nicaragua/overview

\section{Bibliografía}

Alto Comisionado para los Derechos Humanos. Bachelet alerta acerca de la ley de amnistía y la falta de reparación a las victimas de Nicaragua. Recuperado de http://www.oacnudh.org/ nicaragua-bachelet-alerta-acerca-de-la-ley-de-amnistia-y-la-falta-de-reparacion-a-lasvictimas/ 
Amnistía Internacional. Disparar a matar. Estrategias de represión de la protesta social en Nicaragua. 2018. Recuperado de https://www.amnesty.org/download/Documents/ AMR4384702018SPANISH.PDF

Batallón Gilles. Nicaragua (2018-2019). Una crisis revolucionaria. Ponencia presentada en el V Foro Social Sobre Democracias Otras, organizado por el Observatorio de las Democracias: Sur de México y Centroamérica, julio de 2019.

Bauman, Z. Between Us, the Generations. On Generations. On Coexistence between Generations. Barcelona: Fundació Viure i Conviure, 2007.

Caballero, M. y Baigorri, A. ¿Es operativo el concepto de generación? Aposta, Revista de Ciencias Sociales, 56(2013): 21.

Comisión Interamericana de Derechos Humanos. Informe de País: Graves violaciones a los derechos humanos en el marco de las protestas sociales en Nicaragua. 21 de junio de 2018. Recuperado de https://reliefweb.int/report/nicaragua/graves-violaciones-losderechos-humanos-en-el-marco-de-las-protestas-sociales-en

Comité de Liberación de Presos Políticos. Lista Preliminar de Desaparecidos, Presas y Presos Políticos, 19 de marzo de 2019. Recuperado de http://presospoliticosnicaragua.com.

Consorcio Panorama Electora. IV Informe Pre-electoral Sistemático. Nicaragua, 2016. Recuperado de http://cawtv.net/iv-informe-pre-electoral-sistematico-del-consorcio-panoramaelectoral/

Contreras, Jenyel. Entrevista realizada por Red Politik. Recuperado de https://www.youtube. $\mathrm{com} /$ watch? $\mathrm{v}=\mathrm{bkDIL0DQZFQ \& feature=youtu.be}$

Coraza, Enrique y Arriola, Luis. Introducción. Ráfagas y vientos de un sur global: Movilidades recientes en estados fronterizos del sur-sureste de México. San Cristóbal de Las Casas, Chiapas, México: El Colegio de la Frontera Sur: Peter Lang Publishing, Inc., 2018.

Cuadra, E. La transición hacia la democracia en Nicaragua. Democracias en transición en Honduras y Nicaragua. Gobernabilidad, seguridad y defensa. Carlos Barrachina (Coord.), México: Plaza y Valdés, 2009.

Dilthey, W. Introducción a las ciencias del espíritu. México, Fondo de Cultura Económica, 1978a.

Dilthey, W. La comprensión de otras personas y de sus manifestaciones de vida. El mundo histórico. México, Fondo de Cultura Económica, 1978b.

Elpais.cr. (21 de agosto de 2018). Costa Rica crea protocolo para manejo integral de flujos migratorios. Recuperado de https://www.elpais.cr/2018/08/21/costa-rica-crea-protocolo-paramanejo-integral-de-flujos-migratorios/

Flesher, C. y Wood, L. Repression and social movements. Interface: a journal for and about social movements, 3, 1(2011): 1-11.

Franco, F. Clara Victoria electoral del FSLN. Visión Sandinista, 258(2016): 5-6.

Gadea, C. Dos movimentos sociais às experiências coletivas de conflito: acerca das mobilizações e a linguagem da violencia. Movimentos sociais e engajamento politico: Trajetórias e tendencias analiticas (pp. 235-262). Orgs. Ilse Sh. y Lígia H (Eds.). Brasil: Ufsc, 2015.

Gomes, S. Movilizaciones y oportunidades políticas en Nicaragua. Liminar, 16, 2(2018), 17-28.

Gómez-Abarca, C. de J. y Solís, J. Claves para entender la crisis nicaragüense, 2017-2018. En Política y democracia en Centroamérica y México. Ensayos Reunidos. Chiapas, México: ODEMCA-CESMECA-UNICACH, 2019.

Hademos. Informe Situación de Derechos Humanos en Nicaragua, $1^{\circ}$ de octubre de 2018. Recuperado de http://www.hagamosdemocracia.org.ni 
Human Rights Watch. Informe Brutal represión. Torturas, tratos crueles y juicios fraudulentos contra manifestantes y opositores en Nicaragua. Estados Unidos. Recuperado de https://www.hrw.org/es/report/2019/06/19/brutal-represion/torturas-tratos-cruelesy-juicios-fraudulentos-contra

Jarquín, E. Construcción democrática revertida y pervertida. El régimen de Ortega: ¿una nueva dictadura familiar en el continente? Edmundo Jarquín Calderón et al. Managua: PAVSA, 2016.

Jasper, J. Protesto. Uma introdução a os movimentos sociais. Río de Janeiro, Brasil: Zahar, 2014.

La Prensa Latina. (18 de junio de 2019). La oposición de Nicragua demanda la libertad de los "presos políticos" en 36 horas. Recuperado de https://www.laprensalatina.com/ la-oposicion-de-nicaragua-demanda-la-libertad-de-los-presos-politicos-en-36-horas/

La Sexta. (22 de enero de 2019). Habla una estudiante de Medicina en Nicaragua: "Me acusaron de terrorista por ayudar a una familia que murió quemada". Recuperado de https://www.lasexta.com/noticias/internacional/detras-muro/habla-una-estudiantede-medicina-en-nicaragua-me-acusaron-de-terrorista-por-ayudar-a-una-familia-quemurio-quemada-video_201901225c4791430cf2953d8645dd88.html

Mannheim, K. El problema de las generaciones. Revista Española de Investigaciones Sociológicas, 62(1928): 193-224.

Martí i Puig, S. Nicaragua: Desdemocratización y caudillismo. Revista de Ciencia Política, 36, 1(2016).

Martí i Puig, S. Movimientos sociales en Nicaragua (1979-2014): Un caso excepcional. Movimientos sociales en América Latina (pp. 521-538). Almeida, Paul y Allen Cordero (Eds.). Buenos Aires: CLACSO, 2017.

Martí i Puig, S. Nicaragua: análisis de una crisis inesperada. En Documentos de Trabajo, Fundación Carolina, 2019.

Martínez de Codes, R. Reflexiones en torno al criterio generacional, como teoría analítica y método histórico. Quinto Centenario, 3(1982): 51-87.

Meneses, M. El agravio moral como resorte de la acción colectiva. Revista de Estudios Sociales, 57(2016): 43-51.

Meyer, D. Protest and Political Opportunities. Annual Review of Sociology, 30(2004): 125-145.

Naciones Unidas para los Derechos Humanos. Human rights violations and abuses in the context of protests in Nicaragua. Agosto de 2018. Recuperado de https://www. ohchr.org/_layouts/15/WopiFrame.aspx?sourcedoc=/Documents/Countries/NI/ HumanRightsViolationsNicaraguaApr_Aug2018_EN.pdf\&action=default\&DefaultItem Open $=1$

Naciones Unidas para los Derechos Humanos. Actualización sobre Nicaragua en la 41 sesión del Consejo de Derechos Humanos. Julio de 2019. Recuperado de https://www.fidh. org/es/region/americas/nicaragua/actualizacion-sobre-nicaragua-en-la-41-sesiondel-consejo-de-derechos?var_mode=calcul

Norris, P. Young people and democratic institutions: from disillusionment to participation. En Report for the Council of Europe Symposium. Strasbourg, 2003.

Novoa, Alberto. El sistema judicial está siendo usado por el régimen como arma política represiva. Revista Envío, 439(2018). Recuperado de http://www.envio.org.ni/articulo/5539

Ortega y Gasset, J. La idea de las generaciones. El tema de nuestro tiempo. Obras completas. Madrid: Revista de Occidente, 1923. 
Pérez-Islas, J. A. Juventud: un concepto en disputa. Teorías sobre la juventud. Las miradas de los clásicos. José Antonio P., Mónica V. y María S. (Coords.). México: Universidad Nacional Autónoma de México; Miguel Ángel Porrúa, 2008.

Ramírez, S. Adiós muchachos. México: Alfaguara, 2015.

Salgado, M. Activismo de alto riesgo: el Frente Sandinista de Liberación Nacional (FSLN) ¡Patria libre o morir! Anuario de Estudios Centroamericanos, 44(2018): 367-398.

Tarrow, Sidney. El poder en movimiento. Los movimientos sociales, la acción colectiva y la política. España: Editorial Alianza, 1997.

Tilly, Charles. From Mobilization to Revolution. Nueva York: Random House-McGraw-Hill Publishing Co./Reading (Mass.), Addison Wesley Publishing Co., 1978.

Carlos de Jesús Gómez-Abarca. Mexicano. Sociólogo por la Universidad Autónoma Metropolitana y Doctor en Ciencias Sociales y Humanísticas por la Universidad de Ciencias y Artes de Chiapas. Sus investigaciones se abocan a la condición juvenil, los activismos juveniles, la participación política, los procesos electorales y los movimientos sociales en América Latina. Es miembro del Sistema Nacional de Investigadores (c) del Consejo Nacional de Ciencia y Tecnología y miembro honorífico del Sistema Estatal de Investigadores (de Chiapas). Actualmente es investigador del Observatorio de las Democracias: sur de México y Centroamérica, con sede en el Centro de Estudios Superiores de México y Centroamérica, donde también es profesor de los Programas de Maestría y Doctorado en Ciencias Sociales y Humanísticas, integrante de la línea de investigación Política, Globalización y Cambio Sociocultural y miembro del Consejo de Redacción de la Revista Liminar.

Contacto: jesus.gomezabarca@gmail.com

ORCID: 0000-0002-0881-5189 